\title{
Comparative Morphological Study of Pollen Grains and Seeds of Cultivars from the Species Pyrus malus L. and Pyrus communis L. Cultivated in Northern of Iraq
}

\author{
Muna Omer Mohammed Shehab1*, Amer Mohsen Mahmoud Al-Ma'thidy² \\ ${ }^{1,2}$ Department of Biological, College of Education of Pure Science, University of Mosul, Mosul, Iraq \\ E-mail: ${ }^{1 *}$ muna@uomosul.edu.iq, ${ }^{2}$ dr.amer@uomosul.edu.iq
}

(Received May 07, 2020; Accepted June 09, 2020; Available online December 01, 2020)

DOI: 10.33899/edusj.2020.127063.1069, ( $)$ 2020, College of Education for Pure Science, University of Mosul.

This is an open access article under the CC BY 4.0 license (http://creativecommons.org/licenses/by/4.0/).

\begin{abstract}
:
The present research includes a comparative morphological characters of pollen grains and seeds of (8) cultivars belonging the species Pyrus malus L. namely ("EarlyGold", "GrannySmith", "Royal Cala", "Red Delicious", "Golden Delicious", "Honey Crisp", "Mcintosh", Cox") and (6) Cultivars belonge to the species Pyrus communis L. namely ("Coneference", Decana", "Bonica", "Alkhatuni","Alothmani", "William) which cultivated in northern of Iraq. Were examined by light and scanning electron microscope (SEM). The result of pollen grains showed that pattern tricolporate and the shape in polar view triangular or spherical -triangular or tetrangular but in equatorial view spherical or ovate and surface configuration was striate in all cultivars of the species. The morphological characters of seeds (Shape, Color, Dimension of width and Length, Number of seeds in fruit), in addition to indumentum were found to be diagnostic value for separation cultivars from the two species. In addition to its surface configuration, it was Striate in "EarlyGold", "RoyalCala", "Honey Crisp", "Mcintosh" and "Cox" and Striate papillae in GrannySmith, while the "Coneference", "Decana" and "Bonica, Alkhatuni, and Alothmani had a surface configuration pitted, and Irregular Reticular in Red Delicious and Reticulate papillae in cultivar William, while Golden Deliciou was unique as having an alveolate surface, The quantitative and qualitative morphological characters of pollen grains and seeds were found to be diagnostic value for separation cultivars from the species.
\end{abstract}

Keyword: Pyrus L., Pollen grains, seeds.

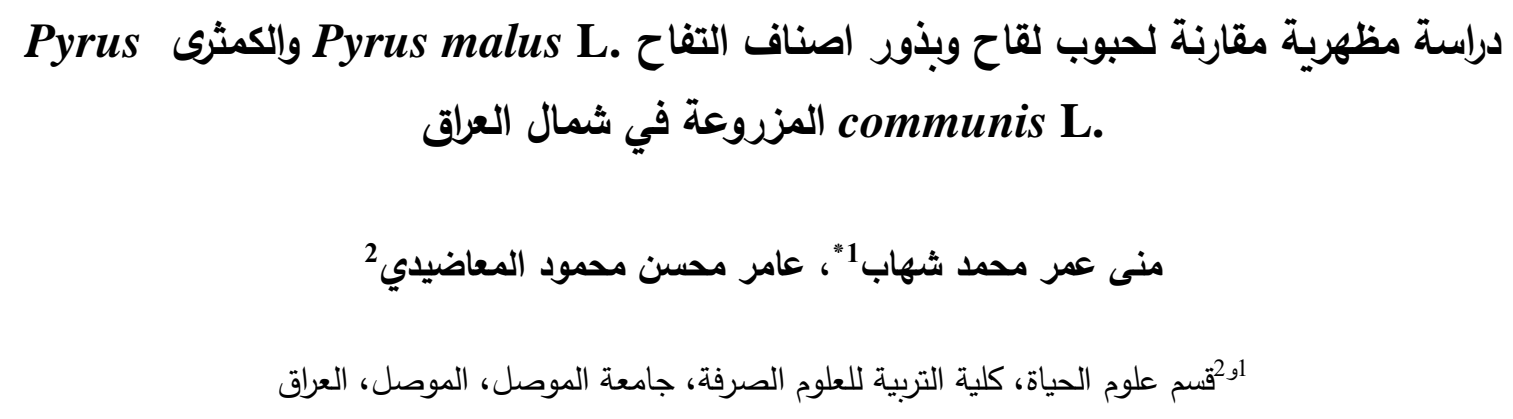


تضـمن البحث الحالي دراسـة تصنيفية مقارنة للصفات المظهرية لحبوب اللقاح Pollen grains والبذور Seeds لــــــ (8)

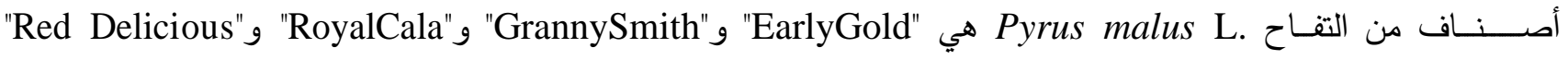

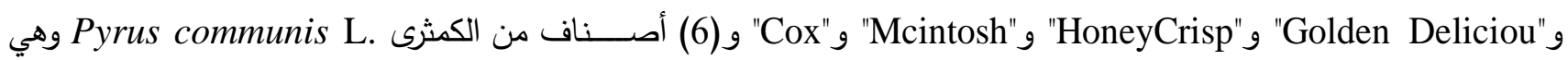
"Coneference" و و"Decana" و"Bonica" و"Alothmani" و و"Alkhatuni" و "William" المزروعـة في شـــــال العراق، التي Scanning electron microscope والمجهر الالكتروني الماسـح Light microscope فحست باسـتخدام المجر الضـئي واظهرت نتائج دراســة حبوب اللقاح بانها من طراز ثلاثية الاخاديد والثقوب Tricolporate وشـكلها في المنظر القطبي

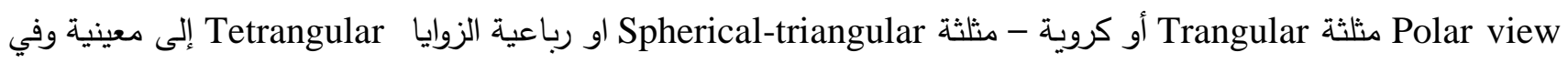
المنظر الاسـتوائي Sphuatorial view كروية Ovate وزخرفتها السـطحية مخططة Striate في St في جميع أصناف النوعين، ودرست الصفات المظهرية للبذور من حيث ابعادها وشكلها ولونها وعددها في الثرة الواحدة، إذ تراوح عددها بين (2-4) بذرة في صنف "Alothmani" و (8-12) بذرة في الصنفين "Golden Delicious" و "William"، فضلا عن زخرفتها السـطحية اذ كانت مخططة Striate في الاصــناف "RoyalCala" و" و" و"Honey Crisp" و و"Mcintosh" و" و"Cox" و" ومخططة ذات حليمات Striate papillae في الصنف GrannySmith"، في حين أن الأصناف "Coneference" و" و" "Decana" و"Aonica" و"Alkhatuni" و"Alothmani" كانت زخرفتها الســـحيـة منقرة Pitted وشـــبكياً غير منتظم Reticulate Red Delicious" وشبكي ذات حليمات صغيرة Reticulate papillae في الصنف William في حين انغرد الصــف "Golden Deliciou" بكونه ذا ســطح منخرب Alveolate، والصـفات المظهرية الكمية والنوعية للبذور وحبوب

$$
\begin{aligned}
& \text { اللقاح أظهرت قيمة تصنيفية في فصل وعزل أصناف النوعين المدروسة. } \\
& \text { الكلمات المفتاحية: جنس Purus، حبوب اللقاح، البذور • }
\end{aligned}
$$

Introduction المقدمة

تعد دراسـة الصفات المظهرية للنبات الركن الاسـاسي في الدراسـات التصنيفية لأنها تمتاز بسهولة ملاحظتها وكثرة تغايراتها مقارنة بالصفات الاخرى مما أكسبها أهمية متزايدة وتعد من أسهل الطرق لتثخيص وتصنيف النباتات, وتمثل الدعامة الاساسية التي يستتد عليها المصـنفون ولا سـيما في الحقل عند التشـخيص الاولي للعينة وعند وضـع مفتاح لعزل المراتب التصـنيفية بعضهـا عن البعض الاخر فضـلاً عن الصـفات التثـريحية والكيميائية والخلوية، فالصـفات المظهرية تعد المرآة التي تعكس الصـفات الوراثية لا سيما تلك التي تظهر ثبوتية أمام التغييرات البيئية [1، 2]. يعد علم حبوب اللقاح Palynology من العلوم البيولوجية المهمة في تحديد وربط العلاقات التطورية والطبيعية بين الانواع والاجناس والعوائل النباتية المختلفة وتعود اهمية حبوب اللقاح إلى عدم تأثرها بالظروف البيئية لذلك فهي مقبولة كمعايير تصــنيفية للتمييز بين الانواع في النباتات الراقية [3]. 
وقد كان للتطور العلمي الذي شــــهد القرن الماضـــي في مجال تصـــنيع الاجهزة الدقيقة كالمجهر الالكتروني الماســـح Transmission electron microscope (TEM) والمجهر الاككتروني النافذ Scanning electron microscope (SEM) دور في تطور علم التصـنيف وتوسـعِِ في دراسـة الصـفات المظهرية والاسـتفادة من جوانب متعددة اكثر دقة في عزل المجموعات النباتية كالجانب التشريحي والكيميائي والجزيئي[4]. من الدراسـات التصنيفية المظهرية دراسـة [5] إذ درس الصفات المظهرية العامة والدقيقة لـــــ (21) نوعا يعود الى العويئلة

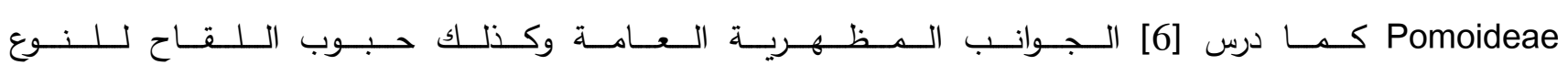
Rosaceae التابع للعائلة الوردية Pyrus pyraster الصفات المهمة، في حين وصف [7] حبوب لقاح ثلاثة أنواع للجنس Pyrus باستخدام المجر الضوئي والالكتروني الماسح. ينتمي التفاح .Pyrus malus L والكمثرى .Pyrus communis L. إلى العائلة الوردية Rosaceae, وهذه العائلة واسـعة الانتشار إذ انها تنتشر في انحاء شاسعة من العالم ولا سيما في النصف الثمالي من كوكب الارض, وهي اكبر العوائل المهمة من الناحية الاقتصادية لا سيما في المناطق المعتدلة [8] لكثرة الفواكه التي تتنجها كالتفاح P.malus والعرموط P.communis والخوخ Prunus pursica

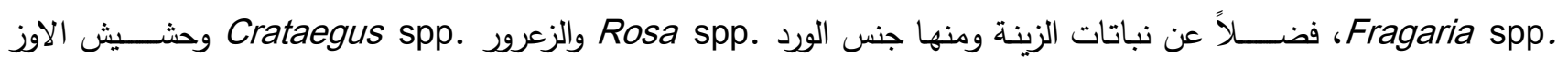

. Potentilla

يعد التفاح والكمثرى من انواع الفاكهة ذات القيمة الغذائية والاقتصادية المهمة في هذه العائلة فضلا عن الاستعمالات الطبية،

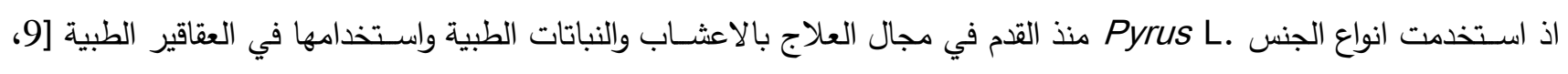
10]، فالتفاح يستخدم في علاج حمى الروماتزم ومرض السكري وفي معالجة السعال وامراض الكبد وكعلاج للاسهال الحاد والمزمن كما يستخدم في الوقاية من خطر الاصـابة بالزهايمر والخرف والسكتة الدماغية، كذلك يقلل من خطر الاصـابة بسرطان الثدي، أما الكمثرى فتسـتخدم اوراقها وثمارها في علاج المسـالك البولية ومدرة للبول والصـفراء وملينة مســلة ويسـتعمل لمعالجة ضــط الدم وتصلب الثرايين وامراض الكلى وامراض الكبد [11، 12].

في الســوات الاخيرة تطورت زراعة العديد من اصــناف الفاكهة منها التفاح والعرموط في العراق وقامت وزارة الزراعة بادخال اصــناف جديدة لنثـر زراعتها وفق برنامج خاص, وتكليف محطات البــتتة والغابات في المحافظات العراقية في انتاج الثــتلات ودراسـة هذه الاصــاف واجراء التجارب عليها، تهدف الدراسـة الحالية إلى تثـخيص اصــاف التفاح والكمثرى المزروعة في شـمال العراق من خلال مقارنة الصفات المظهرية الدقيقة لحبوب اللقاح والبذور وزخرفتها السطحية باستخدام المجهر الضـوئي والاككتروني الماسح (SEM).

Materials and Methods المواد وطرائق العمل

Palynological study أولا: دراسة حبوب اللقاح

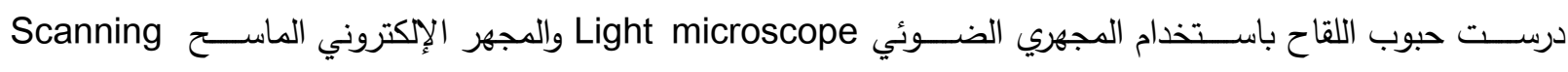
Electron Microscope (SEM) 
إذ ثبتت الازهار والبراعم الناضــــجة بمحلول متكون من ثلاثة حجوم كحول اثيلي مطلق Ethyl alcohol وحجم واحد من حامض الخليك الثلجي Glacial acetic acid لمدة (18-24) سـاعة ومن ثم غسـلت النماذج بكحول اثيلي 70\% وحفظت بكحول بذات التركيز ووضـعت النماذج في الثلاجة لحين اسـتخدامها. بالاضـافة إلى العينات الجافة فقد غليت الرؤوس الزهرية بالماء الحار لمدة

$$
\text { (4-2) دقائق وحضرت الثرائح كالاتي: }
$$

1. اخذت عدد من الزهيرات في بداية التفتح أو البراعم الناضـجة وفتحت على شـريحة زجاجية Slide باسـعمال إبرة تثـريح لأخذ المتوك.

2. وضعت المتوك على شريحة زجاجية ثم وضعت عليها قطرة من السفرانين كليسيرين لمدة (10-20) دقيقة. 3. اخذت المتوك إلى شريحة زجاجية نظيفة وهرست بواسطة ابرتي تشريح دقيقتين لاستخراج حبوب اللقاح ثم وضست عليها قطرة من الصبغة بعد ان ازيلت بقايا المتك ثم وضع غطاء الثريحة Cover slide برفق واصبحت الشريحة جاهزة للفحص. $40 \times$ 年

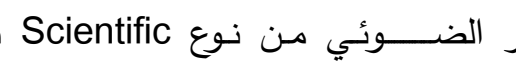

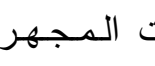

5. درست (20-25) حبة لقاح لكل صنف من اصناف النوعين قيد الدراسـة وتم قياس المحور القطبي Polar axis (P) والمحور الاستوائي (Equatorial axis (E) وحسبت قيمة (P / E) واطوال الاخاديد وسمك الجدار لكل حبة وسجلت اصغر واكبر قيمة

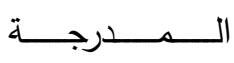
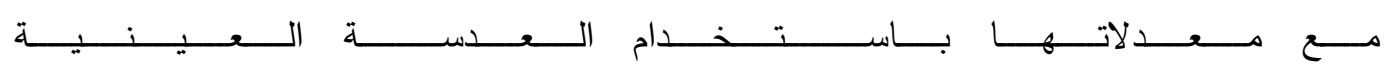

.Ocular micrometer

كما وصـفت اشـكال حبوب اللقاح لكل منها تفصـيلياً وعملت الجداول الخاصــة بالقياسـات التي امكن من خلالها توضـيح التغايرات في المحور القطبي والاستوائي لاصناف النوعين التي تمت دراستها، وتم تصويرها باستخدام العدة الزيتية.

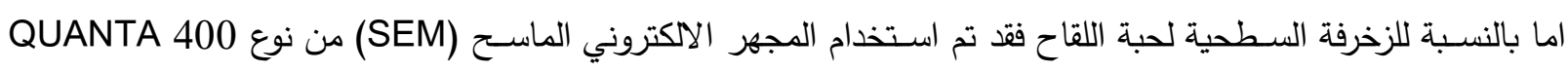
هولندي المنشأ في جامعة السليمانية/ كلية العلوم/ قسم الجيولوجي وحضـرت حبوب لقاح اصناف النوعين المدروسـة حسب طريقة $:[14]$ 1. حُملت حبوب اللقاح على دعامة من الالمينوم بقطر (12.5) ملم.

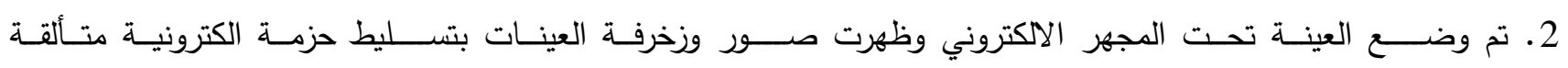
.25-30 Kv. مع تغير مساحة العمل للحصول على افضل الصور وبتكبيرات مختلفة. من خلال فحص العينات تمت معرفة P. malus L.

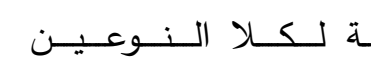

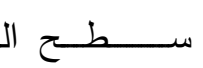

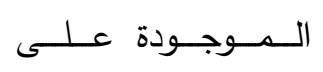

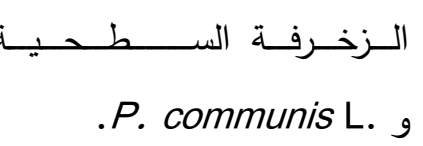
ثانيا: دراسة الصفات المظهرية للبذور اعتمدت الدراسـة الحالية على العينات الطرية التي جمعت من مواقع مختلفة في شمال العراق والمشـصــة من قبل مديريات الزراعة في محافظة نينوى ودهوك التي امكن الوصـول اليها من محطة بستتة نينوى/الثركة العامة للبستنة والغابات ومحطة بستتة 
زاخو/ مديرية زراعة دهوك ومحطة بستنة عقرة/مديرية زراعة عقرة ومنطقة بردرش التابعة لقضاء الثيخان ومنطقة باكيرات في دهوك

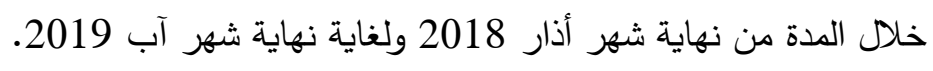

Granny " وهي (إيرلي كولد "Pyrus malus L. جمعت العينات لـ (8) أصناف من التفاح "Royal Cala" رويال كالا", ريد ديليشيص "Red Delicious", كولدن ديليشيص "Golden Delicious", هوني كريسب "Honey Crisp"

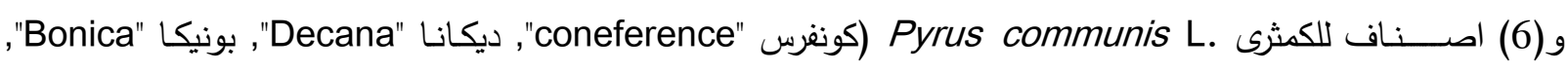
الخاتوني "Alkhatuni", العثماني "Alothmani" ووليم "William" والعائدة لجنس الـ Pyrus المستزرعة في العراق. شملت الدراسة الصفات الكمية والنوعية للبذور التي تمت دراستها باستعمال مجهر التشريح Dissecting microscope من نوع (Wild)، كما استعملت الاوراق البيانية لقياس طول البذرة، والفيرنية الاككترونية Electronic digital caliper لقياس عرضها. تراوح عدد العينات بين 10-15 عينة عشوائية لكل صنف وبين (25- 30) قراءة قياس لكل صفة, واستعملت كاميرا من نوع 16 mega pixels لتصـوير البذور • اما بالنسـبة للزخرفة السـطحية للبذرة seed وغلاف البذرة seed coat فقد تم اسـتخدام المجهر الاككتروني الماسـح (SEM) البذور على دعامة من الالمنيوم بقطر 12.5ملم وظهرت الصــور بتسـليط حزمة الكترونية متألقة 30kv-25. مع تغيير مسـاحة العمل للحصول على افضل الصور وبتكبيرات مختلفة [14].

Results and Discussions النتائج والمناقشة Palynological study اولا: دراسة حبوب اللقاح

أظهرت الدراســــة الحالية أن جميع أصـــناف النوعين المدروســــة ذات حبوب لقاح متماثلة الاقطاب Isopolar متناظرة Symmetrical جميع الاصــاف المدروسـة متوسـطة الحجم, كما تبين أيضــاً أن هنالك تغايراً في ابعادها إذ بلغ معدل طولها في المنظر القطبي (37.77) مايكروميتر في صنف "Early Gold" أما أقصر محور فكان معدله (29.58) مايكروميتر في الصنف "William", إلا أن اطول محور في المنظر الاستوائي سجل في الصنف "Decana" إذ بلغ معدله (42.39) مايكروميتر واقصر محور كان معدله

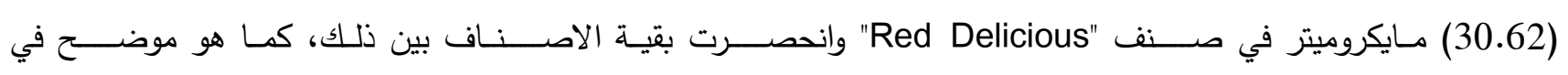
الجدول 1. واستناداً إلى شكل حبة اللقاح في المنظر القطبي (P) Polar view فقد امكن تقسيم الاصناف المدروسة إلى ثلاثة مجاميع كما هو مبين في اللوحة 1:

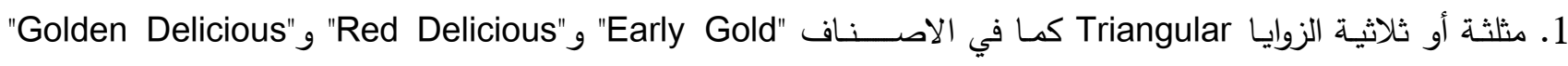

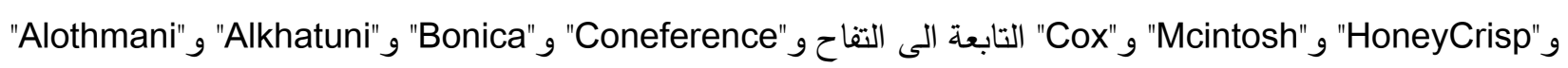
التابعة الى الكمثرى. 
2. كروية- مثلثة Spherical- Triangular في الاصناف "Royal Cala" التابعة الى التفاح و"Decana" و" و"William". 3. رباعية الزوايا Tetrangular إلى معينة كما في صنف "Alothmani" التابعة الى الكمثرى. اما بالنسـبة لثـكل حبوب اللقاح للأصـناف المدروسـة في المنظر الاسـتوائي Equatorial view أمكن تقسـيمها إلى مجموعتين:-

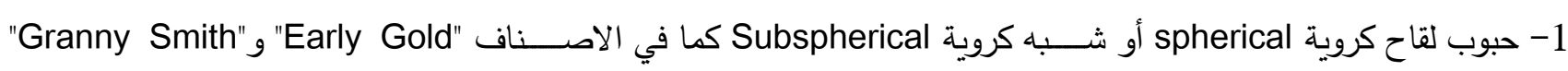

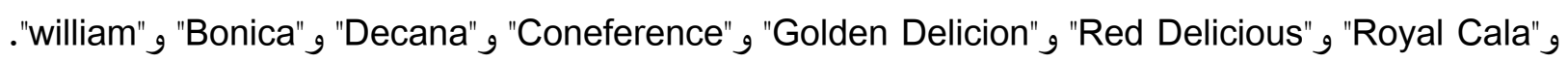

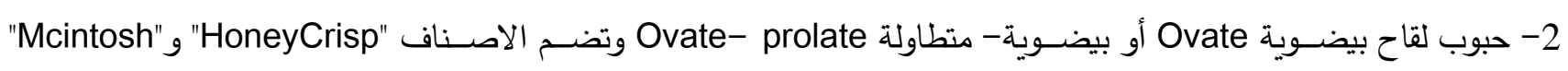

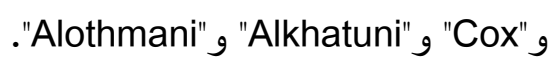
أما بالنسبة لسمك جدار الحبة فقد تراوح معدله بين (1.96) مايكروميتر في حدها الادنى في الصنف "Bonica" و (3.74) مايكروميتر في حدها الاعلى في الصنف "William" وتبدو بشكل مزدوج الطبقات Bilayer شفافة من جهة الثقوب.

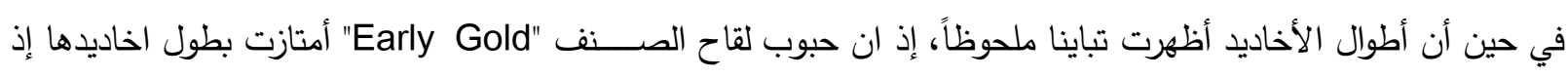
تراوحت بين (8.32- 12.06) مايكروميتر وبمعدل (10.11) مايكروميتر في حين الصنف "William" كانت اطوال اخاديد حبوب لقاحه بين (6.24- 8.32) مايكروميتر وبمعدل (7.32) مايكروميتر وبذلك امتازت حبة لقاح هذا الصـنف بقصـر أخاديدها، وهذا يتماشـى مع ما أكدته دراسـة كل من [16، 17، 18] الذين اشــاروا إلى وجود اختلافات في الصـفات المظهرية لحبوب اللقاح عند دراستهم انواع واصناف عدة من العائلة الوردية Rosaceae. أما من حيث زخرفتها السطحية Surface configuration فقد تبين أنها من النمط المخطط Striate Pattern وتتكون من خطوط تثـبه أخاديد بصــات الاصــابع وفي الغالب مرتبة بشـل متوازٍ في جميع أصـناف النوعين المدروس كما هو موضـح في اللوحة 2.

وهذه النتائج تتفق مع ما اكدته دراسة [19، 20، 21] إذ اشاروا إلى ان حبوب لقاح عدة أنواع من العائلة الوردية تحتوي على ثلاثة اخاديد ذات ثقوب Tricolporate وزخرفتها السطحية مخططة Striate وانسجمت هذه النتائج أيضاً مع دراسة [22] حيث بين أهمية الصفات المظهرية الدقيقة لحبوب اللقاح في تثخيص انواع من الجنس .Rosaceae التابعة للعائلة الوردية Pyrus L. 
جدول (1) الصفات الكمية والنوعية لحبوب لقاح اصناف التفاح Pyrus malus L والكمثرى . Pyrus communis L المدروسة (مقاسة بالمايكروميتر)

\begin{tabular}{|c|c|c|c|c|c|c|c|c|c|c|}
\hline المنظر الاستوائي في & شكل الحبة في & متوسط ابعاد حبة & سمك جدار الحبة & طول الاخدود & $\mathbf{P} / \mathbf{E}$ & المحور الاستوائي & المحور القطبي (P) & & النوع & ت \\
\hline Subspherical & Triangular & $39.52 \times 37.77$ & $\begin{array}{c}3.20 \\
(4.16-2.08) \\
0.68\end{array}$ & $\begin{array}{c}10.11 \\
(12.06-8.32) \\
1.36\end{array}$ & 0.96 & $\begin{array}{c}39.52 \\
(45.76-36.19) \\
2.83\end{array}$ & $\begin{array}{c}* 37.77 \\
(41.6-33.28) \\
* * 2.66\end{array}$ & "Early Gold" & \multirow{8}{*}{ 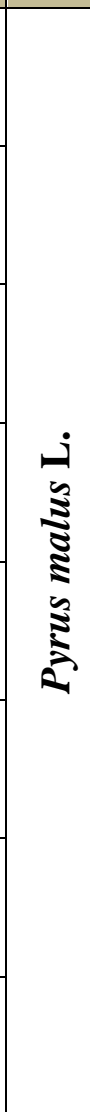 } & 1 \\
\hline spherical & $\begin{array}{l}\text { Spherical - } \\
\text { Triangular }\end{array}$ & $32.45 \times 32.24$ & $\begin{array}{c}2.66 \\
(3.74-1.66) \\
0.83\end{array}$ & $\begin{array}{c}9.03 \\
(10.82-8.32) \\
0.78\end{array}$ & 0.99 & $\begin{array}{c}32.45 \\
(34.94-29.12) \\
2.16 \\
\end{array}$ & $\begin{array}{c}32.24 \\
(34.94-28.70) \\
2.04\end{array}$ & "Granny Smith" & & 2 \\
\hline spherical & $\begin{array}{l}\text { Spherical - } \\
\text { Triangular }\end{array}$ & $37.27 \times 34.77$ & $\begin{array}{c}3.20 \\
(3.74-2.08) \\
0.73\end{array}$ & $\begin{array}{c}9.78 \\
(11.23-8.32) \\
1.11\end{array}$ & 0.93 & $\begin{array}{c}37.27 \\
(41.6-33.28) \\
2.25\end{array}$ & $\begin{array}{c}34.77 \\
(37.44-26.21) \\
3.58\end{array}$ & "Royal Cala" & & 3 \\
\hline Subspherical & Triangular & $30.62 \times 34.24$ & $\begin{array}{c}2.33 \\
(3.74-1.25) \\
0.74\end{array}$ & $\begin{array}{c}9.28 \\
(10.82-8.32) \\
0.87\end{array}$ & 1.12 & $\begin{array}{c}30.62 \\
(33.28-28.70) \\
1.89\end{array}$ & $\begin{array}{c}34.24 \\
(37.44-31.2) \\
1.97 \\
\end{array}$ & "Red Delicious" & & 4 \\
\hline Subspherical & Triangular & $31.28 \times 33.32$ & $\begin{array}{c}2.87 \\
(3.74-1.66) \\
0.77 \\
\end{array}$ & $\begin{array}{c}9.69 \\
(11.65-8.32) \\
1.25\end{array}$ & 1.07 & $\begin{array}{c}31.28 \\
(33.28-29.12) \\
1.91\end{array}$ & $\begin{array}{c}33.32 \\
(34.53-32.86) \\
0.46\end{array}$ & $\begin{array}{l}\text { "Golden } \\
\text { Delicious" }\end{array}$ & & 5 \\
\hline Ovate & Triangular & $40.56 \times 36.52$ & $\begin{array}{c}2.83 \\
(3.74-1.66) \\
0.80\end{array}$ & $\begin{array}{c}8.69 \\
(10.4-7.49) \\
0.86\end{array}$ & 0.90 & $\begin{array}{c}40.56 \\
(45.76-37.44) \\
3.79\end{array}$ & $\begin{array}{c}36.52 \\
(37.44-33.28) \\
1.55\end{array}$ & "Honey Crisp" & & 6 \\
\hline Ovate & Triangular & $32.74 \times 32.28$ & $\begin{array}{c}2.66 \\
(374-1.66) \\
0.74\end{array}$ & $\begin{array}{c}9.48 \\
(11.65-8.32) \\
1.07\end{array}$ & 0.99 & $\begin{array}{c}32.74 \\
(35.36-28.70) \\
1.73\end{array}$ & $\begin{array}{c}32.28 \\
(34.53-29.95) \\
1.62\end{array}$ & "Mcintosh" & & 7 \\
\hline Ovate- prolate & Triangular & $36.19 \times 31.37$ & $\begin{array}{c}2.25 \\
(3.74-1.66) \\
0.65\end{array}$ & $\begin{array}{c}10.07 \\
(11.65-8.32) \\
1.33 \\
\end{array}$ & 0.87 & $\begin{array}{c}36.19 \\
(41.6-29.950) \\
3.91 \\
\end{array}$ & $\begin{array}{c}31.37 \\
(34.94-29.12) \\
2.29 \\
\end{array}$ & "Cox" & & 8 \\
\hline
\end{tabular}


تابع للجدول (1)

\begin{tabular}{|c|c|c|c|c|c|c|c|c|c|c|}
\hline |المنظر الاستوائي & شكل الحبة في & متوسط ابعاد حبة & سمك جدار الحبة & طول الاخدود & $\mathbf{P} / \mathbf{E}$ & $\begin{array}{c}\text { المحور الاستوائي } \\
\text { (E) }\end{array}$ & المحور القطبي (P) & & 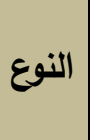 & $ت$ \\
\hline Subspherical & Triangular & $31.28 \times 30.70$ & $\begin{array}{c}3.41 \\
(4.16-2.08) \\
0.67\end{array}$ & $\begin{array}{c}9.86 \\
(11.65-8.32) \\
1.21\end{array}$ & 0.98 & $\begin{array}{c}31.28 \\
(33.28-25.79) \\
2.64\end{array}$ & $\begin{array}{c}30.70 \\
(32.86-28.29) \\
1.42\end{array}$ & "Coneference" & \multirow{6}{*}{ 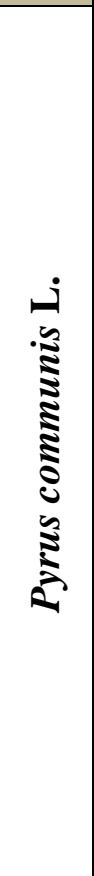 } & 9 \\
\hline Spherical & $\begin{array}{l}\text { Spherical- } \\
\text { Triangular }\end{array}$ & $42.39 \times 37.69$ & $\begin{array}{c}1.99 \\
(2.91-1.25) \\
0.43\end{array}$ & $\begin{array}{c}8.24 \\
(8.74-7.49) \\
0.38\end{array}$ & 0.89 & $\begin{array}{c}42.39 \\
(45.76-37.44) \\
3.08\end{array}$ & $\begin{array}{c}37.69 \\
(43.68-34.11) \\
2.51\end{array}$ & "Decana" & & 10 \\
\hline Spherical & Triangular & $31.87 \times 30.99$ & $\begin{array}{c}1.96 \\
(3.74-1.25) \\
0.76\end{array}$ & $\begin{array}{c}8.03 \\
(8.74-6.66) \\
0.68\end{array}$ & 0.97 & $\begin{array}{c}31.87 \\
(35.36-29.12) \\
2.36\end{array}$ & $\begin{array}{c}30.99 \\
(34.53-29.12) \\
2.13\end{array}$ & "Bonica" & & 11 \\
\hline Ovate & Triangular & $34.28 \times 32.66$ & \begin{tabular}{|c|}
3.12 \\
$(4.16-1.66)$ \\
0.98 \\
\end{tabular} & $\begin{array}{c}9.44 \\
(12.06-7.49) \\
1.64\end{array}$ & 0.95 & $\begin{array}{c}34.28 \\
(37.44-29.12) \\
2.59\end{array}$ & $\begin{array}{c}32.66 \\
(37.44-28.70) \\
2.43 \\
\end{array}$ & "Alkhatuni" & & 12 \\
\hline Ovate & $\begin{array}{l}\text { Triangular- } \\
\text { Teteangular }\end{array}$ & $30.83 \times 32.08$ & $\begin{array}{c}3.37 \\
(4.16-2.08) \\
0.91\end{array}$ & $\begin{array}{c}8.94 \\
(10.81-7.90) \\
1.04\end{array}$ & 1.04 & $\begin{array}{c}30.83 \\
(37.44-27.04) \\
3.35\end{array}$ & $\begin{array}{c}32.08 \\
(35.36-29.54) \\
2.03\end{array}$ & "Alothmani" & & 13 \\
\hline Subspherical & $\begin{array}{l}\text { Spherical- } \\
\text { Triangular }\end{array}$ & $32.69 \times 29.58$ & \begin{tabular}{c|}
3.74 \\
$(4.16-2.08)$ \\
0.68 \\
\end{tabular} & $\begin{array}{c}7.32 \\
(8.32-6.24) \\
0.86\end{array}$ & 0.90 & $\begin{array}{c}32.69 \\
(38.27-24.96) \\
4.72\end{array}$ & $\begin{array}{c}29.58 \\
(33.28-28.70) \\
1.34\end{array}$ & "William" & & 14 \\
\hline
\end{tabular}




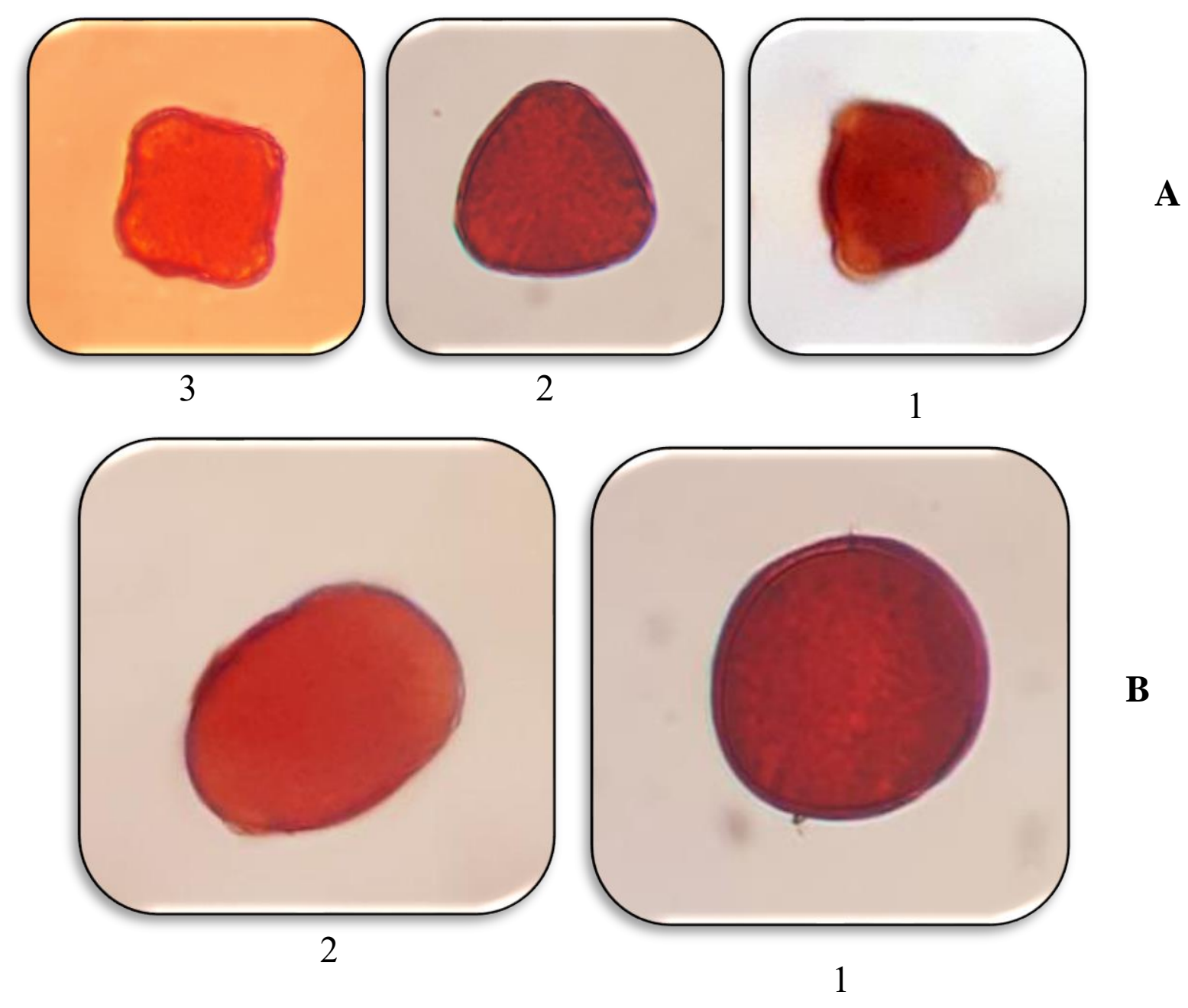

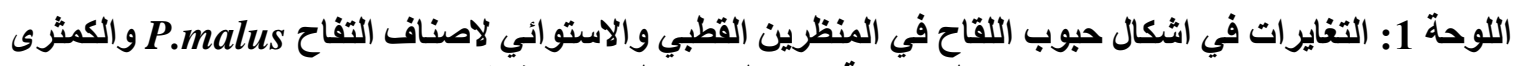

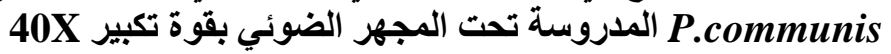

Polar view حبة اللقاح في المنظر القطبي A

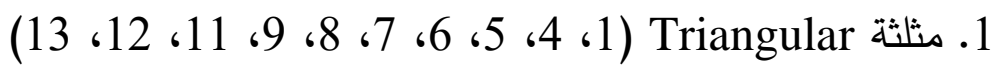
2. كروية -مثلثة Spherical triangular (2، 3، 10، 14) 3. رباعية الزوايا-معينية Tetrangular

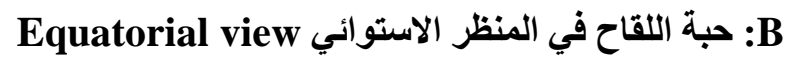
1. كروية أو شبه كروية Spherical - subspherical (1، 2، 3، 3، 4، 5، 5، 9، 10، 10، 11، 14، 14، 2. بيضوية أو بيضوية متطاولة Ovate-Ovate prolate (6، 7، 8، 12، 13

1. "Early Gold"

4. "Red Delicious"

7. "Mcintosh"

10. "Decana"

13. "Alothmani"
2. "Granny Smith"

5. "Golden Delicious"

8. "Cox"

11. "Bonica"

14. "William".
3. Royal Cala"

6. " HoneyCrisp"

9. "Coneference"

12. "Alkhatuni" 

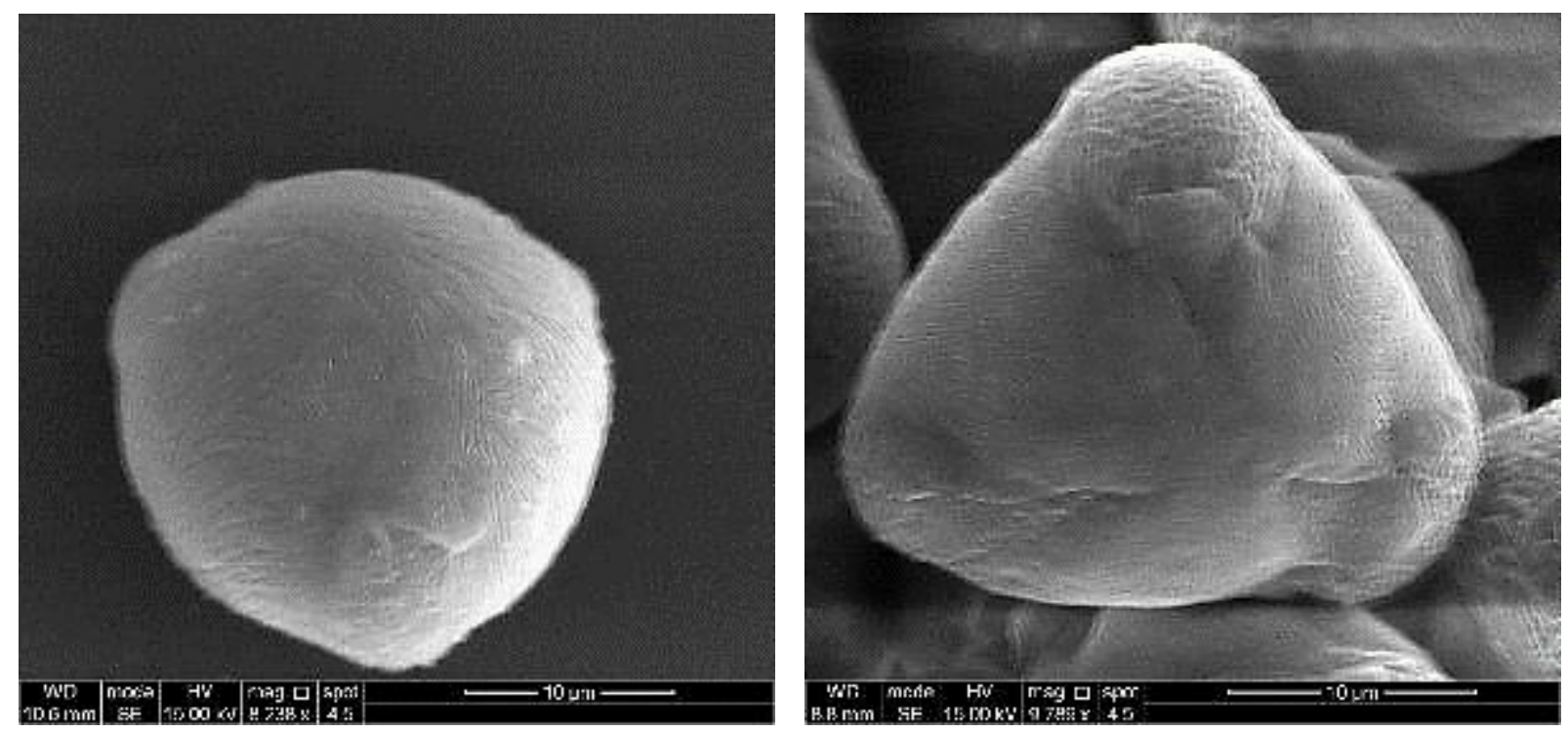

A

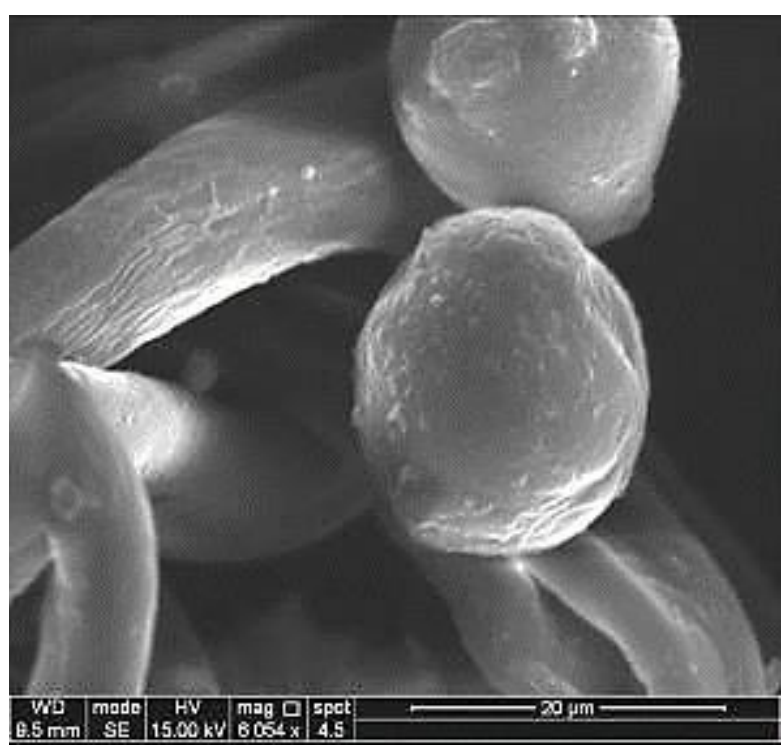

B

اللوحة (2): نوع الزخرفة السطية Surface configuration لحبوب اللقاح في أصناف التفاح والكمثرى المدروسة باستخدام المجهر الاككتروني الماسح (SEM)

Polar view بالة اللقاح في المنظر القطبي A

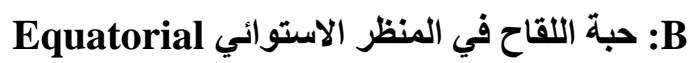

ثانيا: البذرة Seed

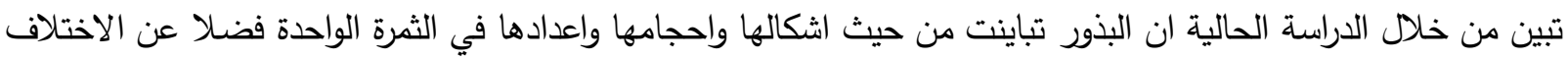

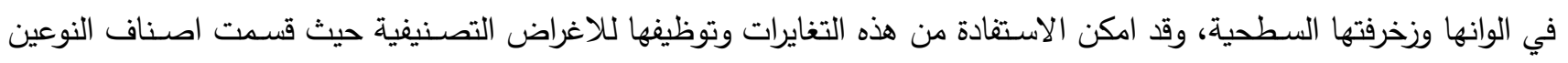
المدروسة حسب شكلها إلى اربعة مجاميع كما هو موضح في الجدول 2 واللوحة 3.

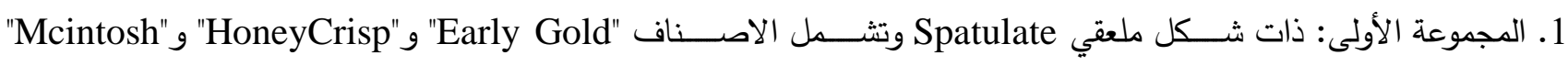

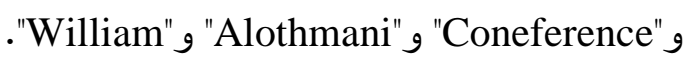


2. المجموعة الثانية: تكون بيضــية ovoid كما في الاصــناف "RoyalCala" و"Red Delicious" و"Golden Delicious"

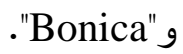

3. المجموعة الثالثة: بيضية ضيقة Narrowly ovoid وتضم الأصناف "Granny Smith" و"Cox" و "Alkhatuni" 4. المجموعة الرابعة: كروية أو شـــبه كروية Spherical-Subspherical كما في الصـــنف "Decana" ومن حيث لونها أمكن تمييزها إلى اربعة مجاميع وهي:-

1. ذات لون أصفر yellow وتضم الأصناف "Early Gold" و "HoneyCrisp" و "Mcintosh" و "Cox" و "Alkhatuni". 2. لونها بني فاتح Light brown كما في الاصـناف "Granny Smith" و"Red Delicious" و"Decana" و"Coneference" و "Wome" و و"Bonica" و و "William"

3. بني Brown كما في الصنغين "Golden Delicious" و و "Alothmani".

4. بني- ضارب إلى السواد brown-blackish في الصنف "Royal Cala".

أما بالنســـبة لأبعادها فكان أعلى طول في الصـــنف "Granny Smith" إذ تراوح ما بين (8.64- 9.92) ملم وبمعدل (9.30) ملم وأدنى قيمة في الصـنف "Golden Delicous" وتراوحت بين (6.77- 8.17) ملم وبمعدل (7.09) ملم وتدرجت بقية

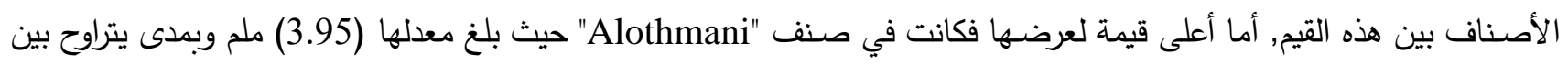

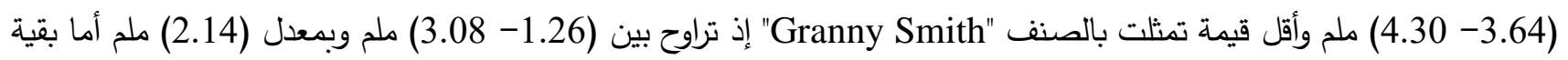
الأصناف فتراوحت بين هذين الحدين، وبالنسبة إلى عدد البذور في الثمرة يشكل أحدى الصفات التمييزية إذ امتلكت ثمار الصنفين

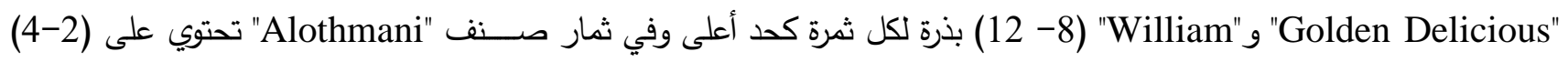
بذرة كدد أدنى وبقية الأصناف عدد بذورها في الثمرة الواحدة تراوح بين هذه القيم وكما هو مبين في الجدول 2.

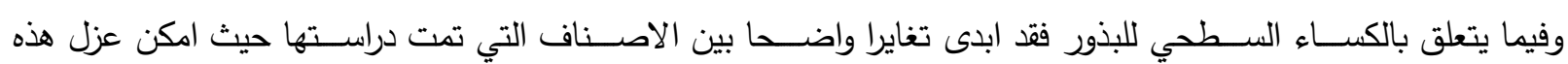

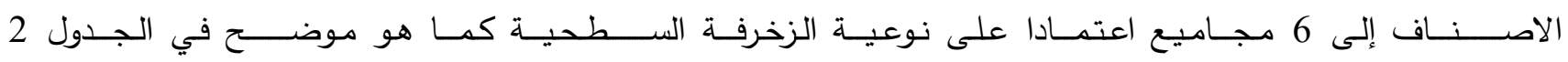
واللوحة 4.

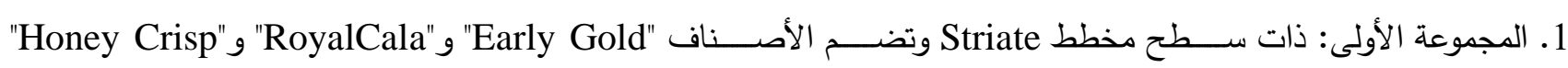
و"Mcintosh" و و" و

2. المجموعة الثانية: سطح مخطط ذو حليمات Striate papillae انفرد بها الصنف "Granny Smith".

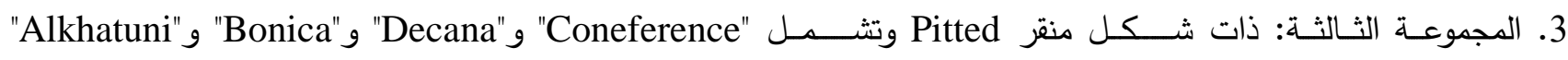
و"Alothmani"

4. المجموعة الرابعة: شبكي غير منتظم Reticulate irregular كما في الصنف "Red Delicious". 5. المجموعة الخامسة: شبكي يحتوي على حليمات صغيرة Reticulate papillae وتتمثل بالصنف "William". 6. المجموعة السادسة: سطح منخرب Alveolate كما في الصنف "Golden Delicious". وهذه النتائج تتفق مع مـا ذكره [17، 23، 24] عن دراســـهم للصـــفات المظهريـة لبعض الانواع التابعة للعائلة الوردية Rosaceae 
جدول (2) الصفات الكمية والنوعية لبذور اصناف التفاح والكمثرى المدروسة (مقاسة بالمليمتر)

\begin{tabular}{|c|c|c|c|c|c|c|c|c|c|}
\hline الزطرفية & لون البذرة & شكل البذرة & عدد البذور في & | معدل الطول| & عرض البذرة & طول البذرة (ملم) & الصفات & النوع & ت \\
\hline Striate & Yellow & Spatulate & $\begin{array}{c}4.5(6-2) \\
1.91\end{array}$ & 4.19 & $\begin{array}{c}2.17(2.66-1.95) \\
0.31\end{array}$ & $\begin{array}{c}* 9.10(9.91-8.47) \\
* * 0.48\end{array}$ & "Early Gold" & \multirow{8}{*}{ 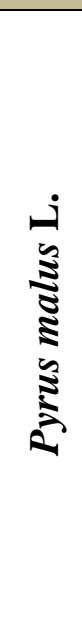 } & 1 \\
\hline $\begin{array}{c}\text { Striate } \\
\text { Papillae }\end{array}$ & $\begin{array}{l}\text { Light } \\
\text { Brown }\end{array}$ & $\begin{array}{l}\text { Narrowly } \\
\text { Ovoid }\end{array}$ & $\begin{array}{c}4.6(7-2) \\
1.95\end{array}$ & 4.35 & $\begin{array}{c}2.14(3.08-1.26) \\
0.62\end{array}$ & $\begin{array}{c}9.30(9.92-8.64) \\
0.37\end{array}$ & "Granny Smith" & & 2 \\
\hline Striate & $\begin{array}{l}\text { Brown- } \\
\text { Blackish }\end{array}$ & Ovoid & $\begin{array}{c}7.75(9-6) \\
1.26\end{array}$ & 2.85 & $\begin{array}{c}3.09(3.60-2.67) \\
0.31\end{array}$ & $\begin{array}{c}8.80(9.50-8.23) \\
0.44\end{array}$ & "Royal Cala" & & 3 \\
\hline $\begin{array}{l}\text { Reticulate } \\
\text { irregular }\end{array}$ & $\begin{array}{l}\text { Light } \\
\text { Brown }\end{array}$ & Ovoid & $\begin{array}{c}7.58(10-4) \\
1.98\end{array}$ & 2.89 & $\begin{array}{c}2.66(3.13-2.38) \\
0.26\end{array}$ & $\begin{array}{c}7.69(8.23-7.23) \\
0.36\end{array}$ & "Red Delicious" & & 4 \\
\hline Alveolate & Brown & Ovoid & $\begin{array}{c}9.63(12-8) \\
0.92\end{array}$ & 2.51 & $\begin{array}{c}2.82(3.37-2.34) \\
0.34\end{array}$ & $\begin{array}{c}7.09(8.17-6.77) \\
0.40\end{array}$ & $\begin{array}{l}\text { "Golden } \\
\text { Delicious" }\end{array}$ & & 5 \\
\hline Striate & Yellow & Spatulate & $\begin{array}{l}6.25(9-4) \\
2.22\end{array}$ & 3.05 & $\begin{array}{c}2.90(3.23-2.16) \\
0.34\end{array}$ & $\begin{array}{c}8.84(9.50-8.09) \\
0.52\end{array}$ & "Honey Crisp" & & 6 \\
\hline Striate & Yellow & Spatulate & $\begin{array}{c}8.16(10-5) \\
1.75\end{array}$ & 2.70 & $\begin{array}{c}3.12(3.40-2.64) \\
0.23\end{array}$ & $\begin{array}{c}8.41(8.87-7.63) \\
0.34\end{array}$ & "Mcintosh" & & 7 \\
\hline Striate & Yellow & $\begin{array}{l}\text { Narrowly } \\
\text { Ovoid }\end{array}$ & $\begin{array}{c}5.2(10-2) \\
3.27\end{array}$ & 2.78 & $\begin{array}{c}2.98(3.48-2.36) \\
0.31\end{array}$ & $\begin{array}{c}8.27(9.65-7.15) \\
0.69\end{array}$ & "Cox" & & 8 \\
\hline Pitted & $\begin{array}{l}\text { Light } \\
\text { Brown }\end{array}$ & Spatulate & $\begin{array}{c}9.42(10-7) \\
1.13\end{array}$ & 2.91 & $\begin{array}{c}.09(4.09-2.08) \\
0.61 \\
\end{array}$ & $\begin{array}{c}9.01(10.20-7.61) \\
0.94 \\
\end{array}$ & "Coneference" & \multirow{6}{*}{ 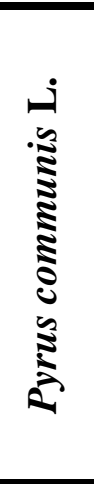 } & 9 \\
\hline Pitted & $\begin{array}{l}\text { Light } \\
\text { Brown }\end{array}$ & $\begin{array}{c}\text { Spherical- } \\
\text { Subspherical }\end{array}$ & $\begin{array}{c}7.42(10-5) \\
2.15\end{array}$ & 2.83 & $\begin{array}{c}2.78(3.39-2.29) \\
0.35 \\
\end{array}$ & $\begin{array}{c}7.88(8.31-7.31) \\
0.41\end{array}$ & "Decana" & & 10 \\
\hline Pitted & $\begin{array}{l}\text { Light } \\
\text { Brown }\end{array}$ & Ovoid & $\begin{array}{c}6.83(9-3) \\
2.14\end{array}$ & 3.07 & $\begin{array}{c}2.47(3.12-2.15) \\
0.74\end{array}$ & $\begin{array}{c}7.60(8.48-6.1) \\
0.74 \\
\end{array}$ & "Bonica" & & 11 \\
\hline Pitted & Yellow & $\begin{array}{l}\text { Narrowly } \\
\text { Ovoid }\end{array}$ & $\begin{array}{c}5(7-2) \\
2.13\end{array}$ & 2.38 & $\begin{array}{c}3.28(3.47-3.07) \\
0.12 \\
\end{array}$ & $\begin{array}{c}7.8(8.38-7.41) \\
0.32 \\
\end{array}$ & "Alkhatuni" & & 12 \\
\hline Pitted & Brown & Spatulate & $\begin{array}{c}2.67(4-2) \\
0.82\end{array}$ & 2.14 & $\begin{array}{c}3.95(4.30-3.64) \\
0.43\end{array}$ & $\begin{array}{c}8.46(9.30-7.89) \\
0.47\end{array}$ & "Alothmani" & & 13 \\
\hline $\begin{array}{l}\text { Pitted- } \\
\text { Papillae }\end{array}$ & $\begin{array}{l}\text { Light } \\
\text { Brown }\end{array}$ & Spatulate & $\begin{array}{c}9.28(12-8) \\
1.60\end{array}$ & 3.88 & $\begin{array}{c}2.20(2.61-1.93) \\
0.24\end{array}$ & $\begin{array}{c}8.54(9.13-7.70) \\
0.54\end{array}$ & "William" & & 14 \\
\hline
\end{tabular}



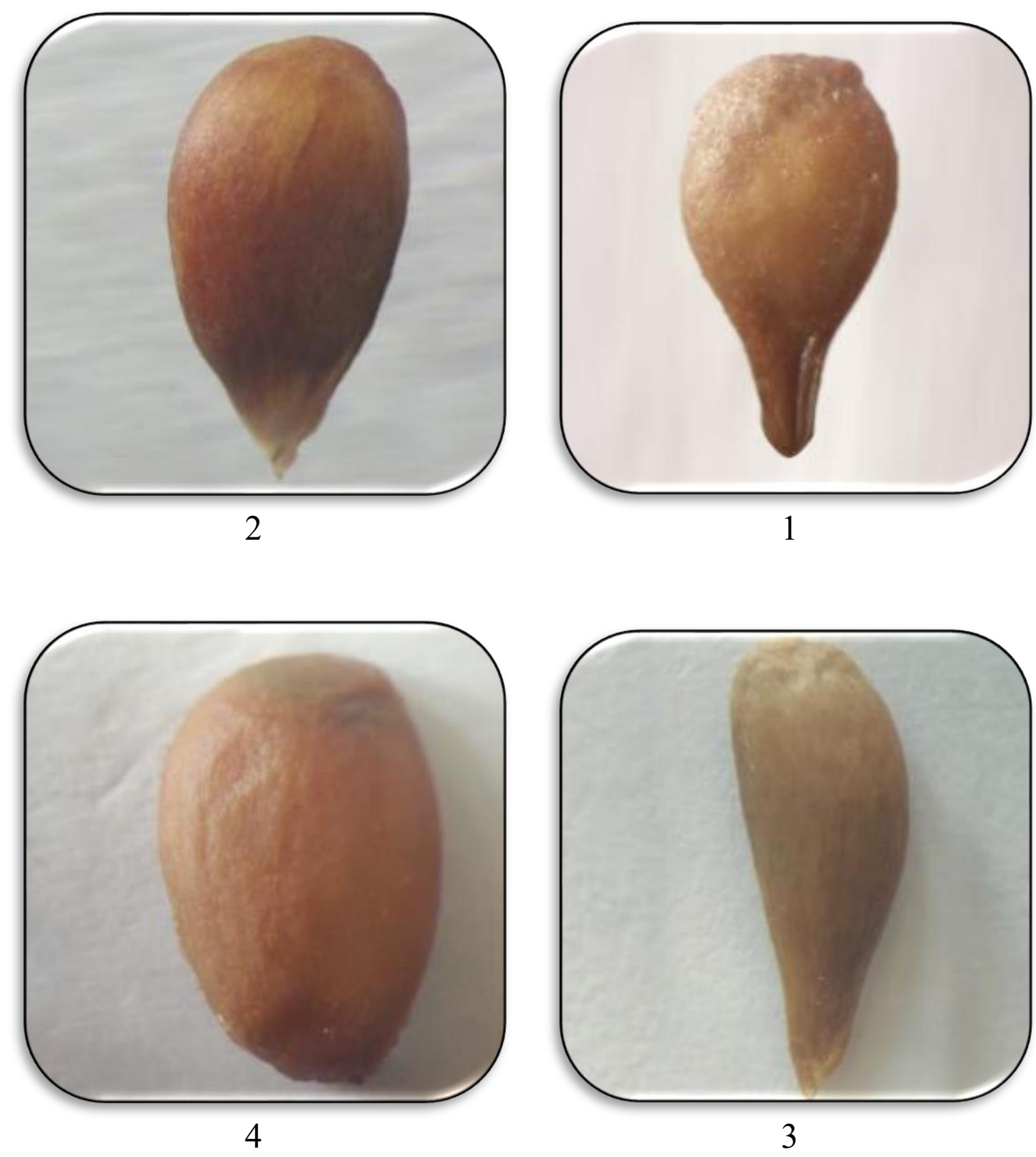

اللوحة 3: اشكال البذور في اصناف التفاح والكمثرى المدروسة باستخدام مجهر التشريح 15X

1. ملعقية Spatulate (1، 6، 7، 9، 9، 13، 13، 14)

2.بيضية Ovoid (3، 4، 5، 11)

3.بيضية ضيقة Narrowly ovid (2، 8، 12)

4. Sروية أو شبه كروية Spherical-Subspherical

1. "Early Gold"

4. "Red Delicious"

7. "Mcintosh"

10. "Decana"

13. "Alothmani"
2. "Granny Smith"

5. "Golden Delicious" 6. " HoneyCrisp"

8. "Cox"

11. " Bonica"

14. "William".
3. Royal Cala"

9. "Coneference"

12. "Alkhatuni" 

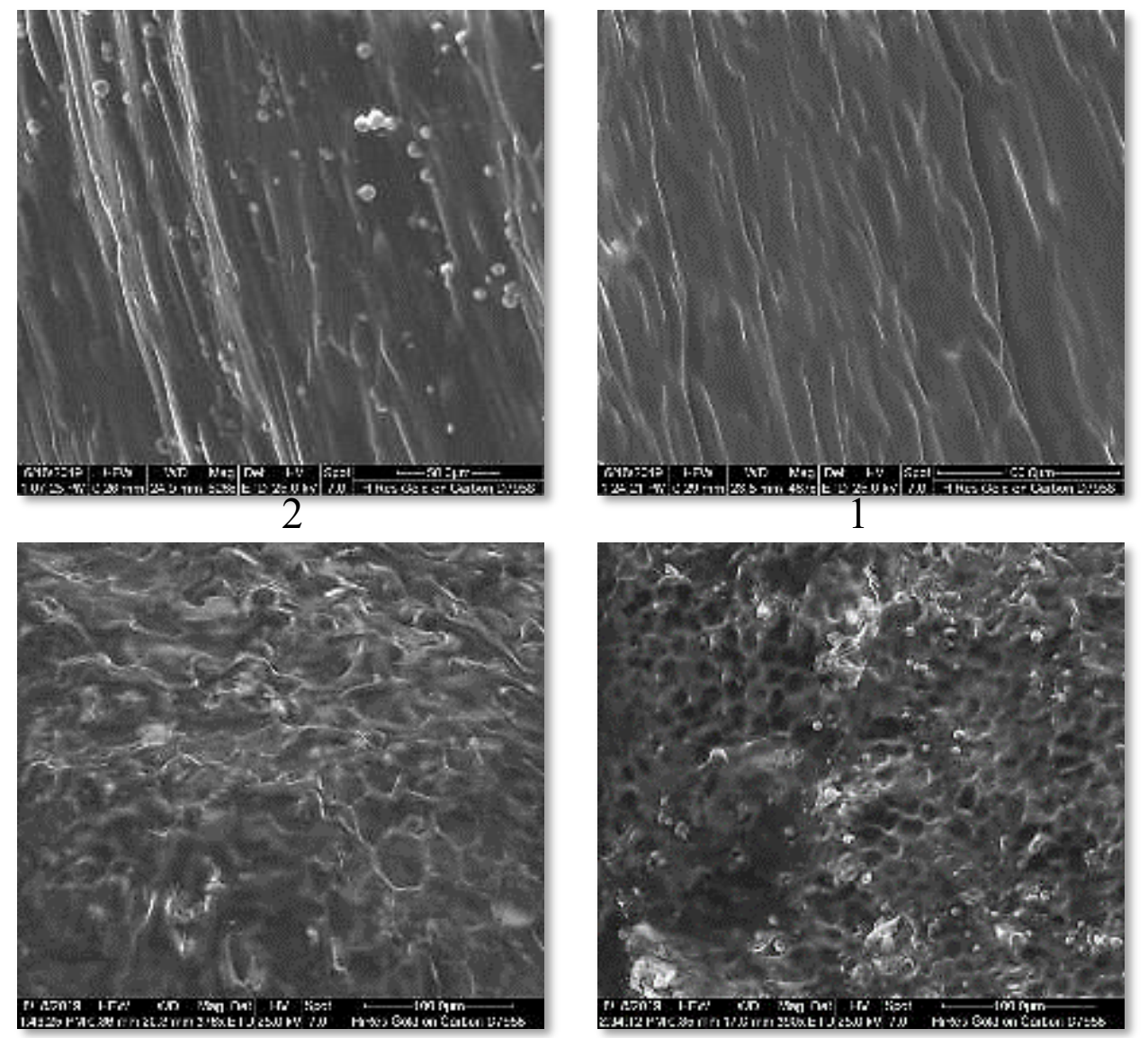

4

\section{3}

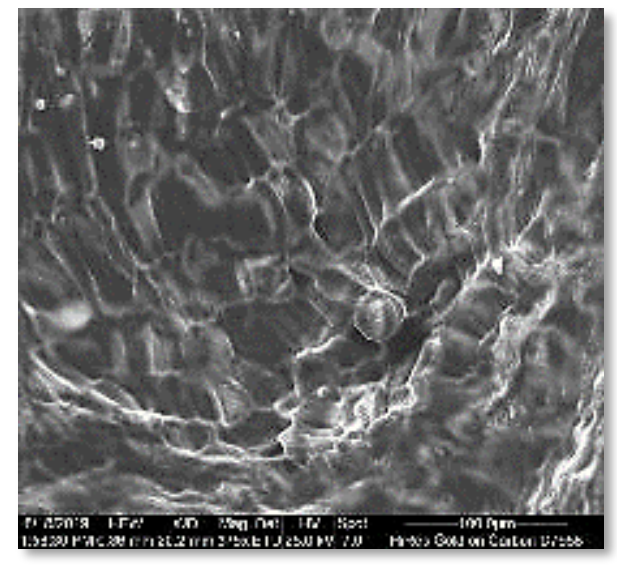

6

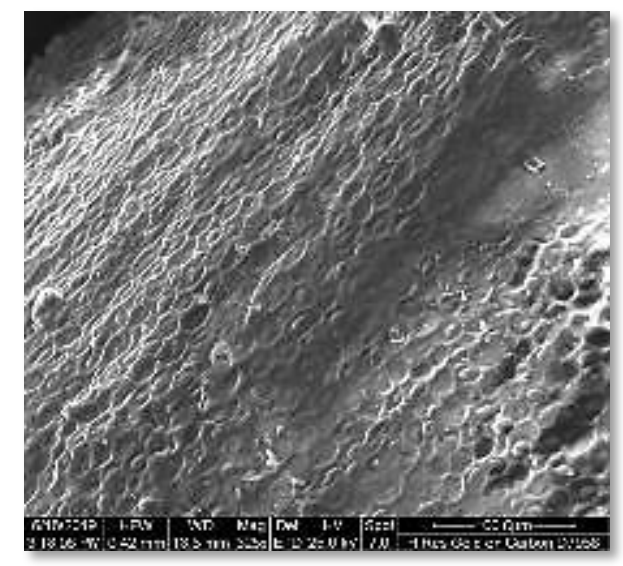

5

اللوحة (4): أنواع الزخرفة السطحية في بذور اصناف التفاح والكمثرى المدروسة

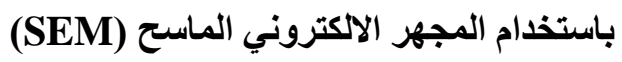




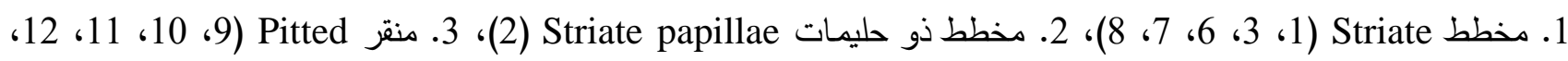
13)، 4. شبكي غير منتظم Reticulate irregular (4)، 5. 1. شبكي ذو حليمات Reticulate papillae (14)،

(5) Alveolate
1. "Early Gold"
2. "Granny Smith"
3. Royal Cala"
4. "Red Delicious"
5. "Golden Delicious" 6. " HoneyCrisp"
7. "Mcintosh"
8. "Cox"
9. "Coneference"
10. "Decana"
11. " Bonica"
13. "Alothmani"
14. "William".
12. "Alkhatuni"

Conclusion الاستنتاجات

امكانية الفصل بين اصناف التفاح والكمثرى المدروسة والتابعة للجنس . Pyrus L بالاعتماد على الصفات المظهرية وخاصة

التي لا تتأثر كثيرا بالبيئة ومن هذه الصفات شكل ولون البذرة، عدد البذور في الثمرة الواحدة، حجم البذرة، كما ان للزخرفة السطحية للبذور اهمية في فصل وعزل الانواع والاصناف المدروسة باستخدام المجر الاككتروني الماسح (SEM) والتي يمكن ان يعول عليها بثكل كبير في الفصل بين اصناف النوعين المدروسة لثبوتها امام التغيرات البيئية، النمط السائد لحبوب اللقاح في جميع الاصناف المدروسـة هو ثلاثي الفتحات والثقوب Tricolporate في المنظر القطبي ومتوسطة الحجم وزخرفتها السطحية من النمط المخطط مثلثة Polar view مشكب Priangular و كروية الى مثلثة Spherical-triangular واو رباعية الزوايا -معينية Tetrangular، اما شـكلها في المنظر الاسـتوائي فكروية او شـبه كروية Spherical-Subspherical او بيضوية - بيضوية متطاولة Ovate-Ovateprolate.

[1] Melderis, A. S., Species problem in Recent Scandinavian Works on Grasses in: J. E. Louslely (ed.) species studies in the British flora. Bot. soc. Br. Is1. London, 140-159 (1955).

[2] Radford, A. E.; Dikison, W. C.; Massey, J. R. and Bell, C. R., Vascular plant systematic. Harper and Row, New York, 891 pp (1974).

[3] Aytug, B., Role of palynology in taxonomy and classification (in Turkish). $J$ for fac Istanbul Univ. Ser B9: 118- 125, Istanbul, Turkey (1959).

[4] Obaid, A.K.A., Morphological Anatomical Study to comparative some species of the genus of Citrus L., M.S.c thesis, College of Education - University of Dhi Qar, (2008) (In Arabic). 
[5] Abdul-Razaq, R.T., Acomparative systematic study of taxa of subfamily Pomaideae (Rosaceae) in Iraqi Kurdistan, Ph.D. Thesis, College of Agriculture, University of Sulaimanya (2008). (In Arabic)

[6] Abdul-Razaq, R.T., Registering new species in Iraq of the Genus Pyrus L. from subfamily Pomoideae (Rosaceae) in Iraqi Kurdistan, Ibn Al-Hatham Journal of Pure and Applied Sciences, 26(2):29-35 (2013). (In Arabic).

[7] Antkowiak, W.; Rutkowska, I. M.; Jedrzejczyk, I.; Wojciechowski, A., Morphological, anatomical and cytological characteristics of spontaneous hybrid pyrus $\times$ myloslavensis. Dendro Biology, 75: 23-30 (2016).

[8] Dirlewanger, E.; Cosson, P.; Tavaud, M.; Aranzana, MJ.; Poizat, C.; Zanetto, A.; Arus, P.; Laigret, F., Development of microsatellite markers in peach Prunus persica (L.) Bactsch and their use in genetic diversity analysis in peach and sweet cherry (Prunus avium L.). Theor Apple Genet 105: 127- 138 (2002).

[9] Al-Hadary, A.A.Z., "Medicine for Every Disease". Herbal Therapy in Encyclopedia, Plants and Medicinal Oils, , Cairo, Madbouly Library (2000) (In Arabic).

[10] Ali. A., The genus Crataegus L. (Rosaceae) with species Reference to Hybridization and Biodiversity in Turkey J. Bot 29. 37 p (2003).

[11] Al-Katib, Y.M., "Taxonomy of Seed Plants". $2^{\text {nd }}$. Ed., Dar Al-Kutub for Printing and Publishing, University of Mosul, Iraq (2000). (In Arabic).

[12] Chopra, R. N.; Nayar, S. L.; Chopra, I. C., Glossary of Indian medicinal plants. Drug research laboratory, Jammua- Kashmir. 206 (2006).

[13] Al- Mayah, A. A., The taxonomy of Terminalia (combretaceae) and related genera. $\mathrm{Ph}$. D. thesis, Univ. of Leicester. U. K. (1983). 
[14] Zamani, A.; Attar, F.; Maroofi, H., Plollen morphology of the genus pyrus (Rosaceae) in Iran. Acta Biologica szegediensis, 54(1): 51-56 (2010).

[15] Erdtman, G., Pollen morphology and plant taxonomy, Angiosperms. An introduction to palynology. Al mgvist and wiksell, Stockholm. 539 pp (1952).

[16] Hua, Z. L., Pollen morphology of Maloideae of china (Rosaceae). Kuming Institute of Botany, The Chinese Academy of sciences, Acta. Botanica Yunnanica vol. 1.22(1): 43-52 (2005).

[17] Faghir, M. B.; Moghaddam, M. A.; Shavvan, R. S., Micro- Macro morphology of the genus Geum L. (Rosaceae) in Iran and their taxonomic significance. Iran. J. Bot, 21(2): $103-117(2015)$.

[18] Al-Jumeily, B.H.A., Acomparative taxonomic study of peach Prunus persica (L.) Batsch Rosaceae cultivars cultivated In Mosul City, Ph.D. thesis, College of Education for Pure Sciences , University of Mosul (2015) (In Arabic).

[19] Chung, K. S.; Elisens, W.J. and Skvarla, J. J., Pollen morphology and its phylogenetic significance in tribe sanguisorbeae (Rosaceae). Plant. Syst. Evol. 285: 139- 148 (2010).

[20] Faghir, M. B.; Attar, F.; Ertter, B. and Eriksen, B., Pollen morphology of the genus Potentill (Rosaceae) in Iran. Acta Botanico Hungarica, 54: 1-16 (2012).

[21] Hasan, H. H., Systematic study of the Genus Potentilla L. (Rosaceae) in kurdistan Region- Iraq. M. SC. thesis, Salahaddin University, Erbil: 118 pp (2019).

[22] Zamani, A.; Attar, F.; Maroofi, H., Plollen morphology of the genus pyrus (Rosaceae) in Iran. Acta Biologica szegediensis, 54(1): 51-56 (2010). 
[23] Tantawy, M. E. and Naseri, M. E., Contribution to the Achene knowledge of Rosoideae (Rosaceae) LM and SEM. I. J. A. B., 2: 105- 112 (2003).

[24] Fredes, M.; Munoz, C.; Part, L.; Torres, F.; Saez, P.; Bustamante, L.; Paiva, L.; Pertuze, R., Seed morphology and anatomy of Rubus geoides SM. Chilean Journal of Agricultural Research, 76 (3): 385-389 (2016). 